\title{
O narrador demoníaco do romance Os tambores silenciosos
}

Loreci Alves Marins"

Miguel Rettenmaier ${ }^{\text {** }}$

\section{Resumo}

Este artigo pretende interpretar a obra Os tambores silenciosos, de Josué Guimarães, em relação à construção de sentidos quanto aos estatutos narratológicos e seus constituintes interpretativos. Assim, focalizando o gênero romanesco, associará dois elementos característicos à narrativa, ora na ordem do narrador, ora no campo dos estudos da personagem. Como diegese, a narrativa que foca na trajetória individual do herói, na sua psicologia demoníaca, de acordo com György Lukács. Para tanto, a condição do personagem, dissociado e em busca, é transmigrada para a função de narrar, característica e complexa no que diz respeito ao romance. Ademais, é necessário considerar os modos da compreensão do romance postulados por Jean Pouillon, na obra $O$ tempo no romance, que propõe a distinção formal de duas visões: "por detrás" e "com”, a partir do olhar das irmãs Pilar, que o leitor acompanha na narrativa. Dessa forma, é necessário compreender a voz que narra e busca algo nos voos dessa perspectiva que tenta desvelar a vida e busca alguma reordenação na degradação do mundo, baseando-se em Todorov no que tange às visões de Pouillon, bem como a perspectiva de Gérard Genette complementa o estudo do narrador, tratando da focalização.

Palavras-chave: Estatutos narratológicos. Gênero romance. Os tambores silenciosos.

\section{Introdução}

A condição e a circunstância de uma personagem literário está intimamente relacionada ao foco narrativo que ilumine a sua existência. Ele é visto, ou se vê, pelas lentes de quem narra. Ele é construído pela palavra de que testemunha e diz. Esses é um elemento que nos faz perceber que o escritor mobiliza recursos em sua narrativa, como diálogo, ação, descrição, de modo a tornar suas criaturas verossímeis na ordem de eventos. Todo um universo, representado pela intensidade dos acontecimentos, passa pelo narrador.

Histórias são narradas desde sempre. Fatos testemunhados por alguém ou vivenciados por outrem, relatos de viagem ou de outros tempos, sempre houve quem, entre a fábula e a recepção,

* Mestra em Letras pela UPF. Atualmente, professora da rede pública e privada. E-mail: lorecialvesmarins@ gmail.com

** Professor PPGL/UPF; coordenador do Acervo Literário de Josué Guimarães; Bolsista de Produtividade em Pesquisa 2 CNPq. E-mail: mrettenmaier@hotmail.com

Data de submissão: ago. 2021 - Data de aceite: out. 2021 http://dx.doi.org/10.5335/rdes.v17i3.12614 
se fizesse presente - o narrador. Dos primórdios da humanidade, nas oralidades e no imaginário dos mitos, nas epopeias, das narrativas de cosmovisão teocêntrica às novelas profanas, da redescoberta do humano à modernidade e à contemporaneidade, a narrativa dialogou com um zeitgeist no qual se personificam valores, esperanças, utopias e desencantos.

No desenvolvimento histórico do romance, nos deslocamentos de seus atributos estéticos pelo tempo, o narrador foi se modificando, se escondendo atrás de outros ou narrando a si próprio, o que imaginou, desejou, viu ou testemunhou. Diferentemente da epopeia, que apresentava um narrador distante do mundo narrado, no romance as relações são feitas pela proximidade dolorosa de um eu com um mundo sem sentido. Há, portanto, um herói dissociado, em busca de valores, cuja trajetória importa mais do que seu destino.

Nesse sentido, Josué Guimarães, escritor e jornalista, tem a palavra e o papel como instrumento de denúncia. Nas finas folhas de papel de jornal, inicialmente, e na impressão de romances, em fase tardia, em uma década e meia de produção literária, exerceu, por toda a vida, o ofício da observação e da crítica. $\mathrm{Na}$ relação entre o ficcional e o factual, como ponto de contato dentre as duas formas de textualizar, a imaginação foi recurso constante.
Os tambores silenciosos, com o qual recebeu o prêmio Erico Verissimo em 1977, foi escrito em Portugal, nos anos 70, quando Josué optou pelo autoexílio fora do Brasil. Apesar disso, a obra quase foi censurada por aqui, haja vista que Josué era um homem visado pela ditatura civil-militar ainda vigente. Romance que traz personagens, aludindo aos poderosos e aos generais da época, a um contexto de repressão. Tudo isso é trazido à tona pelo olhar de sete solteironas, as irmãs Pilar, que dividem sua casa e perspectiva frente à cidade cercada, assim como dividem o espaço discursivo com um narrador que não se identifica, em terceira pessoa, com sujeito ou demônio, mas que parece "voar" nos céus de Lagoa Branca (GUIMARÃES, 2011).

\section{O romance e seus demônios}

Segundo Lukács (2000, p. 72),

[...] o romance, em contraposição à existência em repouso na forma consumada dos demais gêneros, aparece como algo em devir, como um processo.

A tragédia, ainda que transformada, transmutou-se em sua essência até $o$ presente, enquanto que a epopeia teve de desaparecer, dando espaço para o romance, um gênero novo. 
Em primeiro lugar, ela [a estética clássica alemã] tornou evidente o elemento comum que liga o romance à epopeia. Na prática, essa ligação se reduz ao fato de que todo romance de grande significação tende à epopeia, ainda que de modo contraditório e paradoxal-e é precisamente nesta tendência jamais alcançada que ele adquire sua grandeza poética. Em segundo lugar, o significado da teoria burguesa clássica do romance reside na tomada de consciência da diferença entre epopeia e o romance, e, portanto, na compreensão do romance como um genêro tipicamente novo. (LUKÁCS, 1999, p. 198).

Assim, como postulado por Gallo (2012) em sua dissertação de mestrado, sobre A teoria do romance de Lukács, em que a autora faz um comparativo entre a obra e o ensaio $O$ romance como epopeia burguesa, do mesmo autor, ambos os estudos ratificam que

[...] o gênero romanesco ocupa na sociedade burguesa o lugar que a epopeia ocupou no mundo antigo. Entre outras questões, Lukács ainda trata nestes escritos do surgimento do romance, bem como teoriza acerca dos aspectos formais e conteudísticos do gênero (GALLO, 2012, p. 13).

O romance é a epopeia de uma era para a qual a totalidade extensiva da vida não é mais dada de modo evidente, para a qual a imanência do sentido à vida tornou-se problemática, mas que ainda assim tem por intenção a totalidade (LUKÁCS, 2000, p. 55).

Toda a égide da crítica literária de Lukács baseia-se no conceito de forma; "nele convergem os mosaicos da composição artística e a partir dele são ditados os parâmetros da avaliação estética" (LUKÁCS, 2000, p. 174). Assim, a forma é o verdadeiramente social na literatura, sendo, portanto, essencial a ela, pois estabelece relação entre a vida interna e externa, sem a qual não há fenômeno literário.

Segundo Lukács (2000, p. 55), "tanto para a épica quanto para a tragédia [...] o verso é um divisor de águas", pois o verso trágico cria distância, enquanto que na epopeia as distâncias criadas significam leveza, na esfera da vida conduzem à superação. No entanto, essa leveza trata-se de uma utopia imanente da hora histórica. Sendo assim, somente a prosa é capaz de fazê-lo. Ora, a epopeia concebe forma a uma totalidade de vida fechada, a partir de si mesma, enquanto o romance busca descobrir e construir, pela forma, a totalidade oculta da vida. "Assim, a intenção fundamental determinante da forma do romance objetiva-se como psicologia dos heróis romanescos: eles buscam algo" (LUKÁCS, 2000, p. 60).

O processo segundo o qual foi concebida a forma interna do romance é a peregrinação do indivíduo problemático rumo a si mesmo, o caminho desde o espaço cativeirona realidade simplesmente existente, em si heterogênea e vazia de sentido para o indivíduo, rumo ao claro autoconhecimento. Depois da conquista desse autoconhecimento, o ideal encontrado irradia-se como sentido vital da imanência da vida, mas a discrepância entre ser e dever-ser não é superada, e tampouco poderá sê-lo na esfera em que tal se desenrola, a esfera vital do romance; só é possível acançar um máximo de aproximação, uma profunda e intensa iuminação do homem pelo sentido de sua vida (LUKÁCS, 2000, p. 82).

Não obastante, a estética clássica alemã foi além para classificar o romance, Segundo Lukács (1999, p. 200), seu 
mérito "imorredouro" para a teoria do romance reside na descoberta da profunda relação que liga o romance como gênero à sociedade burguesa”. Para a épica não é necessário considerar o passado do herói, explicar seu caráter ou a sua relação com a sociedade, haja vista que ele pode ter sua narrativa iniciada a partir de um ponto mais favorável ao desenrolar dos eventos épicos. Diferentemente, para o herói do romance o passado é fundamental para explicar geneticamente o presente. Para Lukács, a forma do romance está baseada também pela economia e luta de classes, uma vez que essas incidirão na mudança de um herói que representa o coletivo, na epopeia, para um herói em que cada indivíduo representa uma luta de classes ou um sujeito dissociado na sociedade moderna:

Uma vez surgida a sociedade de classes, a grande arte narrativa só pode extrair sua grandeza épica da profundidade e tipicidade das contradições de classe em sua totalidade dinâmica. Na figuração épica, estas oposições se encarnam sob a forma de luta dos indivíduos na sociedade. Disso resulta, em particular no romance burguês mais tardio, a aparência de que o tema principal seria a oposição entre o indivíduo e a sociedade. Mas se trata apenas de uma aparência. A luta dos indivíduos entre si ganha objetividade e verdade somente porque os personagens e os destinos dos homens refletem de modo típico e fiel os momentos centrais da luta de classes (LUKÁCS, 1999, p. 207).

Sendo assim, "o romance moderno nasceu da luta ideológica da burguesia contra o feudalismo" (LUKÁCS, 1999, p. 213). Trata-se de uma luta simultânea contra o feudalismo e contra a iminente degradação burguesa. A partir do século XVIII, os escritores voltaram sua preocupação para o cotidiano, para tornarem-se historiadores da vida privada pela escritura ficcional. O íntimo e o privado, as incursões na interioridade, no cotidiano sem grandes experiências, tudo o quanto possa ser lenbrado em torno da imagem do indivíduo, se coverte na outra faceta de um mesmo tipo sujeito: o que está só, o que busca sentido, o que não partilham, com o mundo, as mesmas intenções perante valores socialmente consagrados.

\section{Uma forma de desenhar o mundo}

O crítico literário Pouillon (1974) postula que, ao procurar analisar as posições de existência dos personagens, são-lhe determinadas as visões possíveis e psicologicamente análogas às visões das pessoas vivas, tal como, a partir destas últimas, poderia um psicólogo determinar os processos da criação romanesca.

Este estudo vai se encaminhar em várias direções; com efeito, um personagem pode ser colocado diferentemente e, por conseguinte, ser visto de muitas maneiras. Esta variedade não representa um privilégio do romance em face de uma realidade que seria sempre unívoca; ela existe igualmente na vida real. Eis porque mostraremos a propósito de cada modalidade de compreensão que seu valor deriva de seu possível uso real. (POUILLON, 1974, p. 52). 
Pouillon apresenta uma visão fenomenológica do mundo a uma teoria das visões na narrativa associada com a questão do tempo:

Em primeiro lugar, dentro da perspectiva clássica, que distingue um "dentro", a própria realidade psíquica, e um "fora", que constitui a manifestação objetiva dessa realidade (POUILLON, 1974, p. 53).

Para Pouillon, o papel da compreensão consiste em captar esse "dentro", inserindo-se de forma direta nele. No entanto, isso pode ser realizado de duas formas: a visão "com" - ou que, defasando-se com relação a essa realidade, o autor procure analisá-la - é a visão "por detrás”. O “de fora”, pode ser descrito de maneira objetiva, somente interessando à medida que revela o “dentro". Na visão "de fora", o narrador renuncia inclusive ao saber que a própria personagem tem, restringindo-se a descrever os acontecimentos.

$\mathrm{Na}$ visão "com", o narrador escolhe um personagem central para, a partir dele, apresentar os outros. É o que ocorre na narrativa de Os tambores silenciosos, em que o narrador privilegia o olhar das irmãs Pilar e é através do olhar delas que se vêm a conhecer as outras personagens bem como os acontecimentos. Dessa forma, há um narrador que, no início do foco narrativo, está "com", isto é, não conhece totalmente, mas tem com as personagens a mesma consciência irrefletida de si mesmo.
Escolhe-se um único personagem que constituirá o centro da narrativa, ao qual se atribui uma atenção maior ou, em todo caso, diferente da que se atribui aos demais. Descrevemo-lo de dentro; penetramos imediatamente a sua conduta, como se nós mesmos a manifestássemos. Por conseguinte, essa conduta não é descrita tal como se afiguraria a um observador imparcial, mas tal como se apresenta, e apenas na medida em que se apresenta, àquele que a manifesta. (POUILLON, 1974, p. 54).

Não obstante, essa expressão "único personagem" não é muito exata, senão que deve implicar o sentido de personagem central.

De um modo geral, num romance "com", 0 centro a partir do qual se irradia a visão constitui um foco que faz parte do próprio romance; é na obra que se encontra a fonte de luz que a ilumina (POUILLON, 1974, p. 62).

Há semelhanças com o narrador onisciente neutro, em que o narrador fala em terceira pessoa, que é um recurso típico dos romances do século XIX e XX. Sobre o foco narrativo, técnicas narrativas não podem ser tratadas como um fim, mas como meios de alcançar efeitos no leitor.

Com efeito, se essa é a visão no início do foco narrativo - a visão "com" - o que se segue é um narrador que levanta voo e assume uma visão "por detrás". Invés de se situar no interior de um personagem, o autor pode tentar distanciar-se para ou considerar de maneira mais objetiva e direta a vida psíquica da personagem, ou, em Os tambores silenciosos, elevar seu olhar a espaços impossíveis à personagem com a qual de início se encontra- 
va, até a visão "por detrás, pela qual o narrador domina todo um conhecimento e assume um aspecto divino. Nessa obra de Josué Guimarães, o narrador parte de um delimitado lugar para tornar-se como uma espécie de espectador privilegiado, que conhece "o lado interior das cartas".

O romancista está "por detrás". Com isto pretendemos dizer duas coisas: por um lado, que ele não se encontra em seu personagem, mas sim distanciado dele; por outro lado, que a finalidade desse distanciamento é a compreensão imediata dos móveis mais íntimos que o fazem agir; graças a esta posição, ele vê os fios que sustentam o fantoche e desmonta o homem. Em suma, não é o herói que se mostra ao romancista, impondo-lhe a visão que ele deverá ter; o romancista é que escolhe a sua posição de ver o personagem. Tudo isso, evidentemente, é metafórico: afirma-se de um indivíduo decidido a adquirir uma consciência clara de si mesmo, se reflete; afirmar-se-á então muito naturalmente que, visto nos encontrarmos "por detrás" dele, podemos ver diretamente o que só lhe é dado ver distanciando-se com relação a si mesmo (POUILLON, 1974, p. 62).

Trata-se de uma visão direta do psíquico sem intermediário. Sem dúvida, não se tem a mesma percepção do psíquico que de um objeto físico, pois há um empenho para caracterizar essa visão com a imaginação. Na reflexão, a visão é direta porque,

[...] embora desdobrada, a consciência conserva-lhe não obstante a unidade: ela própria é aquilo que chega a atingir, ela é o que vê "por trás"; se estivéssemos então "com" o personagem que se reflete (POUILLON, 1974, p. 63).
Sendo assim, não é como na visão "com", em que se vê o segundo através dos olhos do primeiro, antes, há na visão "por trás" uma espécie de encontro de duas séries diferentes. Trata-se de uma imaginação que conserva o outro longe "de mim" para que "eu" não me dissolva nele, conservando a dualidade do "visto e do vidente".

Dessarte, de acordo com Bittencourt (1999), os modos de compreensão da ficção como homólogo ao que real, conforme postulado por Pouillon (1974), precisam ser ampliados, haja vista que não devem ter um nivelamento entre o real e o imaginário, pois desconsidera $\mathrm{m}$, também, as disparidades entre experiência e visão do narrador em relação ao leitor. A prática crítica evidencia que somente essas visões são insuficientes para atender às possibilidades do foco narrativo, embora tenham descrito seus aspectos mais importantes. Dessa forma, Todorov (2006) aborda a questão do "ponto de vista" ou das "visões", pautando-se, no entanto, na base linguística, inexistente em Pouillon (1974).

É fácil ver, nessa perspectiva, qual a classificação das visões que podemos adotar: ela corresponde, mais ou menos, à que Jean Pouillon tinha proposto em seu livro Temps et roman: ou o eu do narrador aparece constantemente através do ele do herói, como no caso da narrativa clássica, com um narrador onisciente; é o discurso que suplanta a história; ou o eu do narrador fica inteiramente apagado atrás do ele do herói; estamos então diante da famosa "narração objetiva", tipo de narrativa praticada sobretudo pelos au- 
tores americanos de entre as duas guerras: nesse caso, o narrador ignora tudo de sua personagem e vê simplesmente seus movimentos, seus gestos, ouve suas palavras; é pois a história que suplanta o discurso; ou enfim o eu do narrador está em igualdade com o ele do herói, ambos são informados do mesmo modo sobre o desenvolvimento da ação; é o tipo de narrativa que, aparecida no século XVIII, domina atualmente a produção literária; o narrador se apega a uma das personagens e observa tudo através de seus olhos; chega-se aí, precisamente nesse tipo de narrativa, à fusão do eu e do ele em um eu que conta, o que torna a presença do verdadeiro eu, o do narrador, ainda mais difícil de apreender (TODOROV, 2006, p. 62).

Na obra Os tambores silenciosos há um narrador que está "com", conforme as visões de Pouillon (1974), num primeiro momento, em que os saberes do narrador e das personagens estão no mesmo nível, como afirma também Todorov (2006). Entretanto, a seguir, o narrador levanta voo na narrativa, de acordo com Todorov (2006, p. 62): "o eu do narrador aparece constantemente através do ele do herói", correspondendo à "visão por detrás", postulada por Pouillon. Nesse sentido, ainda, faz-se necessário complementar este estudo com o modo de pensar o narrador proposto por Genette (1995).

$\mathrm{O}$ autor define cada um dos três aspectos daquilo que denomina "realidade narrativa”. Os aspectos são a história, a narrativa e a narração. A história, segundo Cardoso (2013), diz respeito à diegese, ou seja, ao significado, ao conteúdo narrativo que pode ser real ou imaginário. A história é composta pela sucessão de ações. O conceito de narrativa refere-se ao discurso, ao enunciado e ao texto narrativo. Ainda segundo Cardoso (2013, p. 60 ), "É evidente que o discurso tem como alicerce a história e localiza-se no ponto de passagem entre ela e a narração. Dos três aspectos da realidade narrativa, o segundo põe-se exatamente como elo intermediador das extremidades (história e narração) dessa realidade”. Neste viés, o termo discurso é usado para referir-se à narrativa materializada em caracteres gráficos. Logo, de acordo com Genete (1995), fica clara a dependência desses aspectos na narrativa.

Ademais, Genette (1995) contribuiu para ampliar o conceito de narrador com a focalização, pois identificou as duas categorias respectivamente como modo e voz. A voz é considerada a instância que designa as relações entre narração e discurso e, ao mesmo tempo, entre narração e história. A voz é o aspecto da ação verbal considerada nas suas relações com 0 sujeito. Para a comunicação narrativa, o sujeito pode ser aquele que realiza ou sofre a ação, ou ainda, aquele que a relata e, eventualmente, os partícipes nessa atividade narrativa. Segundo Cardoso (2013, p. 62), sobre Genette (1995),

A voz revela-se, portanto, pela instância produtiva do discurso, isto é, pela narração. $\mathrm{O}$ estudo da voz deve sempre se religar às categorias do tempo da narração, do nível da narrativa e da "pessoa", isto é, às relações dessas categorias com o narrador e com a história que conta. 
Bittencourt (1999) esclarece que, dentro da categoria voz, Genette (1995) inclui as relações entre a instância narrativa e o objeto narrado. Dentro delas estão situadas as relações temporais, as de subordinação e a pessoa que conta a narrativa (o narrador). As primeiras se elucidam por

[...] anterioridade, posterioridade ou simultaneidade do narrador em relação àquilo que narra; as relações de subordinação existem entre dois discursos que se situam em níveis narrativos diferentes, compreendendo aí as narrativas dentro da narrativa, as narrativas encaixadas (BITTENCOURT, 1999, p. 121).

Ademais outros tipos de inserções mais sutis.

Outrossim, contar uma história (real ou fictícia) é a função essencial da narrativa. O interesse do teórico direciona-se para a forma, ou seja, para a maneira como a história é produzida e chega ao leitor. Essa preocupação é estudada na categoria de modo, como denominada por Genette (1995) e explanada por Cardoso (2013, p. 61):

[...] assim, a narrativa pode: $1^{o}$ ) fornecer ao leitor mais ou menos pormenores, de forma mais ou menos direta; $2^{\circ}$ ) parecer manter-se à maior ou menor distância daquilo que conta e $3^{\circ}$ ) escolher o regulamento da informação que dá, segundo a capacidade de conhecimento da parte interessada na história, isto é, da personagem ou do grupo de personagens.

A narrativa pode adotar ou fingir adotar a "visão" ou o "ponto de vista" da parte interessada, parecendo tomar esta ou aquela perspectiva em relação à história. São esses aspectos chamados por Genette (1995) de focalização. Conforme Bittencourt (1999), a focalização é então considerada sob três pontos: um discurso em que o narrador "diz mais do que sabe qualquer uma das personagens, ou discurso não focalizado"; se o narrador diz somente o que sabe a personagem, o discurso é de focalização interna, podendo ser neste caso fixa, variável ou múltipla; se o narrador diz "menos do que sabe a personagem", o discurso é de focalização externa. A essa tríplice tipologia podem ser associados os três tipos de Pouillon, "por detrás", "com" e "fora". Assim, as variações do ponto de vista ocorridas ao longo das narrativas acontecem, segundo Genette (1995), devido às mudanças de focalização. A restrição de campo compreendida no conceito de focalização do referido autor indica que, para a sua realização, existe sempre uma seleção ou escolha entre várias possibilidades de conteúdo daquilo que será narrado.

Isso sugere, dentro do modo, um conceito amplo de focalização, que aumenta as suas possibilidades de significação, pois permite a inclusão de posicionamentos afetivos, morais éticos e ideológicos que, por sua vez, repercutirão na construção dos diferentes elementos do mundo ficcional. A focalização aborda o conhecimento que o narrador possui a 
respeito da história em comparação ao conhecimento que a personagem tem. Genette (1995, p. 189) adverte que a focalização

[...] nem sempre se aplica ao conjunto de uma obra, portanto, mas antes a um segmento narrativo determinado, que pode ser muitíssimo breve.

De qualquer forma, o narrador existe graças a um alguém que decide contar uma história. Esse alguém, a quem já se declarou morto, tem uma vida e muitas angústias, uma existência e várias indagações. José Saramago, em "O autor como narrador", parece contestar as compartimentações que, com as melhores intenções, tentam salvar o autor, mas acabam traindo o escritor e as coisas em que acredita o autor. Para o escritor de Ensaio sobre a cegueira,

[...] a figura do narrador não existe, e de que só o autor exerce função narrativa real na obra de ficção, qualquer que ela seja, romance, conto ou teatro (1997, p. 41).

\section{E continua:}

Aceito, até, a probabilidade de variantes ou desdobramentos de um narrador central, com o encargo de expressarem uma pluralidade de pontos de vista e de juízos considerada útil à dialéctica dos conflitos. A pergunta que me faço é se a obsessiva atenção dada pelos analistas de texto a tão escorregadias entidades, propiciadora, sem dúvida, de suculentas e gratificantes especulações teóricas, não estará a contribuir para a redução do autor e do seu pensamento a um papel de perigosa secundaridade na compreensão complexiva da obra. (SARAMAGO, 1997, p. 38).
Para o autor português, um livro é a expressão de seu autor, da mesma forma como o autor está no livro todo:

$\mathrm{O}$ que o autor vai narrando nos seus livros é, tão-somente, a sua história pessoal. Não o relato da sua vida, não a sua biografia, quantas vezes anódina, quantas vezes desinteressante, mas uma outra, a secreta, a profunda, a labiríntica, aquela que com o seu próprio nome dificilmente ousaria ou saberia contar (SARAMAGO, 1997, p. 41).

O livro é como um sonho, ou resulta como que de muitos sonhos, tomados ou não de empréstimo ou particulares. $\mathrm{O}$ sonhador pode e está no narrador que constrói tão inconformado e resistente quanto um quixote.

\section{O narrador demoníaco}

Na narrativa da obra Os tambores silenciosos, Josué Guimarães faz uso do discurso indireto livre, dissipando a separação rígida entre a câmera e as personagens, conferindo autonomia de conhecer a interioridade dos ambientes que não poderia ser captada pela observação externa das irmãs Pilar.

O narrador em terceira pessoa simula um registro contínuo, focalizando a personagem em momentos precisos que interessam ao andamento da história e à materialização dos seres que a vivem (BRAIT, 1993, p. 53).

Dessa forma, deixa-se de ter um narrador "com", como determinado por Pouillon (1974), para acompanhar o voo do narrador, que assume a visão "por detrás". 
Na visão "por detrás", o narrador personagem encontra-se não mais dentro do mundo representado, mas por detrás, "como um demiurgo ou um espectador privilegiado que conhece o lado inferior das cartas" (POUILLON, 1974, p. 62). O narrador conhece tudo sobre os personagens e sua circunstância, interioridade, passado e futuro; é, portanto, onisciente. Neste caso, segundo Pouillon (1974), o escritor é quem escolhe a sua posição para ver o personagem, conforme observado no trecho a seguir:

Por isso [as irmãs Pilar] não chegaram a ver quando, protegido pela escuridão da Rua do Soturno da Alta, distante uma quadra da casa delas, o Vereador Paulino Paim aguardava impaciente que de sua casa saísse o jovem Rubem Müller, um dos líderes da Ação Integralista local, filho do dono da fábrica de sabão da Rua da Cruz, a "Teuto-Brasileira" acompanhando o abrir da porta, o beijo de despedida dado na sua mulher e esperando por momentos que o ruído dos seus passos se perdesse na noite silenciosa (GUIMARÃES, 2011, p. 25).

A voz do narrador ultrapassa os limites impostos às lentes do binóculo das irmãs Pilar. A partir do foco dado pelo binóculo, o narrador parte, adentrando às alcovas. Ademais, o narrador levanta voo na narrativa, de acordo com Todorov (2006, p. 62), "o eu do narrador aparece constantemente através do ele do herói" correspondendo à "visão por detrás", postulada por Pouillon (1974). A exemplo, há a passagem em que Maria Madalena afirma não ver mais devido ao telhado do
Baratilho da Lagoa, e ao leitor, mesmo assim, é permitido acompanhar o que se passa. "O Ford passou no portão entre a porta de serviço da Prefeitura e a parede do prédio da Câmara de Vereadores;" GUIMARÃES, 2011, p. 12).

Outro exemplo é encontrado, à medida que as forças externas aparecem para romper com a ordem imposta do Cel. Cândido Braga, como observado pelas irmãs Pilar, na saída dos representantes do município de pijamas rumo à casa do prefeito. Através do binóculo, é apresentada a cena, mas que só é desenvolvida pelo narrador. As irmãs Pilar dizem "Lá vai também o Capitão Ernesto, para mim é revolução que anda por aí e revolução de chumbo grosso" (GUIMARÃES, 2011, p. 74). A indignação das irmãs revela a urgência dos acontecimentos, chegando elas a cogitar a morte do prefeito, dadas as circunstâncias.

No entanto, o narrador desenvolve a cena acima descrita, cujo foco partiu das irmãs. $O$ que se segue é a entrega do papel pelo telégrafo Ezequiel ao prefeito. Trata-se de um telegrama urgente da capital que visa apurar denúncias de abuso de autoridade e censura. O prefeito Cândido Braga, irritado, percebe a urgência de se responder àquele chamado e não esconde o desejo de impor sua vontade em relação aos assuntos internos do município, mas, como político que é, percebe a necessidade de ponderar. Em resposta, esquiva-se da 
responsabilidade, atribuindo as "falácias" aos comunistas.

Como postulado por Todorov (2006), é fácil ver, nessa perspectiva, qual a classificação das visões que podem ser adotadas: ela corresponde, mais ou menos, à que propunha Pouillon (1975), segundo os estudos de Todorov (2006, p. 62):

[...] ou o eu do narrador aparece constantemente através do ele do herói, como no caso da narrativa clássica, com um narrador onisciente; é o discurso que suplanta a história.

Ainda nesse viés de análise, faz-se necessário complementar essa relação entre narrador e personagem através da perspectiva de Genette (1995) sobre a focalização, como considerada sob os três pontos citados anteriormente: o discurso não focalizado; o de focalização interna, podendo ser fixa, variável ou múltipla; e o discurso de focalização externa. $\mathrm{Na}$ obra em questão, há um narrador que sabe mais do que qualquer personagem, em momentos específicos.

A passagem em que as irmãs Pilar observam que o Dr. Lúcio saiu de casa às pressas, sendo que há pouco havia chegado da prefeitura, evidencia que, naquele momento, o narrador tem mais conhecimento dos fatos. Tais acontecimentos giram em torno da apreensão, pelo prefeito, da carta de D. Benigna, esposa de Dr. Lúcio, destinada à irmã que mora em Porto Alegre. Ele se sente envergonhado, chega em casa e, pela insistência da mulher em saber o que houve, confronta-a. O que as irmãs Pilar observam é a consequência disso: Dr. Lúcio não suportou ficar em casa, logo, aplica-se a esse narrador um discurso não focalizado.

Esses excertos evidenciam como o modo de narrar proposto por Genette (1995) pode adotar ou fingir adotar a "visão" ou o "ponto de vista" da parte interessada, parecendo tomar esta ou aquela perspectiva em relação à história. O desfecho da narrativa evidencia a escolha desse narrador, cujo discurso é não focalizado: o momento do suicídio do prefeito de Lagoa Branca, no qual não há observador que tenha acesso à cena.

Acendeu a luz, correu para junto da parede onde haviam caído os bichos, pegou num deles, arrancou as penas, rasgou os panos que cobriam a armação de arame, começou a rir, tirava chumaços de algodão e de lã, depois jogou tudo longe, recarregou a arma, sentou-se na cadeira atrás da mesinha, apoiou a culatra no chão de tijolos, enfiou os dois canos na boca e comprimiu os gatilhos. (GUIMARÃES, 2011, p. 217).

Por fim, Bittencourt (1999) esclarece que, dentro da categoria "voz", Genette (1995) inclui as relações entre a instância narrativa e o objeto narrado. Dentro delas, estão situadas as relações temporais, as de subordinação e a pessoa que conta a narrativa (o narrador). As primeiras se elucidam por 
[...] anterioridade, posterioridade ou simultaneidade do narrador em relação àquilo que narra; as relações de subordinação existem entre dois discursos que se situam em níveis narrativos diferentes, compreendendo aí as narrativas dentro da narrativa, as narrativas encaixadas (BITTENCOURT, 1999, p. 121-122).

A forma de narrar Os tambores silenciosos é repetida durante todas as introduções de capítulos: primeiro, o narrador situa o objeto narrado, para depois emprestar o foco e a opinião para a irmã que estiver em seu turno para a observância da cidade, através do binóculo. No entanto, o foco narrativo pertencente às irmãs, quando estas se encontram à janela para avistarem o movimento da cidade, é bastante reduzido. De modo que, para adentrar ambientes e expor diálogos, o narrador deve vestir sua onisciência, apresentando uma relação temporal de posterioridade do narrador em relação ao objeto narrado. Exemplo disso é o momento da descoberta, pelo Dr. Fadul, da cegueira de Maria da Glória.

- Cega, doutor? - exclamou Maria de Jesus - mas a Maria da Glória sempre foi cega, doutor; ela já nasceu cega.

O médico fez um ar de espanto, disse que nunca ouvira nada a esse respeito, elas nunca haviam dito nada e na cidade, ele podia jurar, ninguém sabia disso. (GUIMARÃES, 2011, p. 215).

O narrador deste romance funciona como uma câmera (BRAIT, 1993) que, a partir do foco do olhar das irmãs Pilar, dá a conhecer o microcosmo de Lagoa Bran- ca bem como traz à existência suas personagens. Não obstante, pôde-se observar que esse narrador da obra assume um caráter onisciente, através da visão "por detrás" (POUILLON, 1974), sendo capaz de adentar às alcovas e desnudar tudo o que se passa. Essa aproximação, como o movimento que parte de um binóculo, representa a focalização (GENETTE, 1995) e permite avaliar o conhecimento do narrador em relação às personagens e o inverso.

\section{Considerações finais}

Portanto, a questão fulcral - o narrador - está presente na análise, ora focando na trajetória do herói, na sua psicologia demoníaca, de acordo com Georg Lukács (1970), ora na condição do personagem, transmigrado para a função de narrar. Na obra em análise, percebe-se que o narrador alça voos a partir do olhar das irmãs, adentrando às alcovas. Logo, esse narrador sabe mais que qualquer uma das personagens, de modo que se tornou necessário entendê-lo no ato de assumir a visão "por detrás”, como postulado por Pouillon (1974).

A voz do narrador ultrapassa os limites impostos às lentes do binóculo das irmãs Pilar. A partir do foco dado pelo binóculo, o narrador parte, adentrando os espaços. Ademais, o narrador levanta voo na narrativa; segundo Todorov (1970), “o eu do narrador aparece através 
do ele do herói” (TODOROV, 1970). Ainda nesse viés de análise, fez-se necessário complementar essa relação entre narrador e personagem através da perspectiva de Genette (1995). Na obra em questão, há um narrador que sabe mais do que qualquer personagem, em momentos específicos.

Logo, entender as visões de Pouillon (1974) dentro da narrativa de Os tambores silenciosos bem como a escolha do modo de narrar, como a escolha da focalização proposta por Genette (1995), se fazem mister. Ao mesmo tempo, é importante saber algo essencial que produz um entrechoque na teoria quanto aos voos do narrador que acontecem sobre Lagoa Branca. De certa forma, há uma contravenção na escolha desse narrador de mais de um tipo, sua forma de ser, partindo do olhar de um espaço delimitado para um voo pelos céus da cidade sitiada, de tornar-se produto de olhos cegos, além do alcance de quem pode ver, traz um novo sentido a esse narrador demoníaco.

Nesse sentido, este narrador é uma proposta de cisão com a ordem, com a hierarquia, com o imposto. Tanto quanto um quixote que cavalga por um mundo hostil de sonhos, o narrador de Lagoa Branca sobrevoa um mundo que precisa ser reparado, e é, pelo menos por um tempo. As ditaduras teimam em retornar, os governos de força constantemente tendem a se apresentar como alternativa no mundo quando nos sentimos inseguros. Contra essas ordens que se impõem, sobretudo, pela violência, há que existir um sonhador que resista. Lauro Schirmer, jornalista e amigo de Josué Guimarães, certa vez, afirmou:

E assim como D. Quixote arremeteu, “dando de esporas em seu cavalo Rocinante, sem atender as vozes que seu escudeiro Sancho lhe dava, advertindo que eram moinhos de vento e não gigantes", Josué marcou quixotescamente muitos lances de sua vida, no jornalismo e na política, mas sem se converter, jamais, num cavaleiro de triste figura. Quixotesco muitas vezes, sim, mas um cavaleiro de notável figura. (SHIRMER, L., 2006).

\section{The demonic narrator of the novel Os tambores silenciosos}

\section{Abstract}

This article intends to interpret the work Os tambores silenciosos, by Josué Guimarães, in relation to the construction of meanings regarding the narratological statutes and their interpretative constituents. Thus, focusing on the romantic genre, it will associate two characteristic elements to the narrative, sometimes in the order of the narrator, sometimes in the field of character studies. As a diegesis, the narrative focuses on the hero's individual trajectory, on his demonic psychology, following the thoughts according to György Lukács. To this end, the character's condition, dissociated and in search, is transmigrated to the function of narrating, characteristic and complex with regard to the novel. Furthermore, it is necessary to consider the 
ways of understanding the novel postulated by Jean Pouillon, in the work O tempo no romance, which proposes the formal distinction of two visions: "behind" and "with", from the perspective of the Pilar sisters, who the reader follows in the narrative. In this way, it is necessary to understand the voice that narrates and seeks something in the flights of this perspective that tries to unveil life and seeks some reorganization in the degradation of the world based on Todorov with regard to Pouillon's visions, as well as the perspective of Gérard Genette complements the study of the narrator, dealing with focusing.

Keywords: Narratological statutes. Romance genre. Os tambores silenciosos.

\section{Referências}

BITTENCOURT, Gilda Neves da Silva. O ato de narrar e as teorias do ponto de vista. Revista Cerrados, Brasília, v. 8, n. 9, p. 107-124, 1999. Disponível em: https:// periodicos.unb.br/index.php/cerrados/article/ view/1001/866. Acesso em: 26 fev. 2021.

CARDOSO, Afonso Ligório. Focalizador e narrador em Genette. Acta científica, Engenheiro Coelho, v. 22, n. 2, p. 59-66, maio/ago. 2013. Disponível em: https:// revistas.unasp.edu.br/actacientifica/article/ view/48/48. Acesso em: 26 nov. 2020.

GALLO, Renata Altenfelder Garcia. A teoria do romance e $O$ romance como epopeia burguesa: um estudo comparado da concepção de Romance em Georg Lukács. 2012. Dissertação (Mestrado em Teoria e Crítica Literária) - Instituto de Estudos da Linguagem, Universidade Estadual de Campinas, Campinas, 2012.
GENNETE, Gérard. O discurso da narrativa. Trad. Fernando Cabral Martins. 3. ed. Lisboa: Veja, 1995.

GUIMARÃES, Josué. Os tambores silenciosos. Porto Alegre: L\&PM, 2011.

LUKÁCS, György. $O$ romance como epopeia burguesa. In: CHASIN, J. (org.). Ensaios Ad Hominem I: tomo II: música e literatura. Santo André: Estudos e edições Ad Hominem, 1999. p. 193-243.

LUKÁCS, György. A teoria do romance. Tradução de José Marcos Mariani de Macedo. São Paulo: Editora 34: Duas Cidades, 2000.

POUILLON, Jean. O tempo no romance. São Paulo: Cultrix, 1974.

SARAMAGO, J. O autor como narrador. Revista Ler, n. 38, Lisboa, Primavera/Verão de 1997.

SCHIRMER, Lauro. Um cavaleiro de notável figura. Zero Hora, Porto Alegre, 18 março de 2006.

TODOROV, Tzvetan. As estruturas narrativas. Trad. Leyla Perrone-Moisés. 3. reimpr. da 4. ed. São Paulo: Perspectiva, 2006.

WATT, Ian. Os mitos do individualismo moderno. Rio de Janeiro: Jorge Zahar, 1997. 